\title{
Darwin and Visual Culture
}

\author{
Lynn K. Nyhart
}

Voss, Julia, 2007. Darwins Bilder. Ansichten der Evolutionstheorie 1827 bis 1874. Frankfurt a. M.: Fischer Taschenbuch Verlag, 379 S., $12.95 €$, ISBN-13: 978-3596176274.

Smith, Jonathan, 2006. Charles Darwin and Victorian Visual Culture. Cambridge: Cambridge University Press, 378 S., 64 f, ISBN-13: 978-0521856904.

What happens when the rising wave of visual cultural studies meets the seemingly endless flow of Darwin studies? These two books show that the resulting whitecaps can ripple out in rather different directions, reminding us that both "visual culture" and "Darwin studies" themselves comprise richly diverse currents. Both books offer serious, innovative contributions to Darwin scholarship, and they overlap far less than one might expect.

In his autobiography, Darwin famously wrote that as he grew older, he lost any aesthetic sensibilities he may once have had, including any "taste for pictures" (p. 138). The appearance of just one illustration in the Origin of Species - the famous "branching tree" diagram - would seem to confirm Darwin's logocentrism. Yet as both Julia Voss and Jonathan Smith point out, Darwin's other publications, both before and after, were rich in illustrations - indeed, their numbers grew from book to book. Both authors show how Darwin tapped into existing traditions in visual culture while developing them in new directions suited to his purposes. Beyond this common theme in their analyses, Voss and Smith take very different approaches to analyzing Darwin's figures.

Voss organizes her book around what she calls four "iconic pictures" from Darwin's works: the four Galapagos finches from the 1845 second edition of the Journal of Researches (better known as the Voyage of the Beagle); the branching tree diagram from the Origin (1859); the series of images of the eye-spotted tail-feathers of the Argus pheasant in The Descent of Man (1871); 
and the laughing macaque from Expression of the Emotions in Man and Animals (1872). Although only the first two of these images are "iconic" in the sense of being instantly recognizable representations of Darwin's thought to a broader public today, the group is iconic in two important senses. First, all four visually represent key ideas of Darwin. The Galapagos finches represent gradualistic variation; the branching tree represents the process of evolution and the underlying basis of classification; the Argus pheasant's eyespots stand for the claim that complex, even seemingly perfect structures could derive from selection (in this case, sexual selection); and the laughing monkey represents the continuity between humans - formerly understood as the only beings able to laugh - and nonhuman primates. Second, and even more centrally, Voss uses these images as icons for the varied genres of illustration which Darwin made use of and bent to his own purposes: bird illustrations, classificatory diagrams, series, and human and animal portraits. Voss explores the roots of Darwin's four images in earlier conventions and their transformations by Darwin to support his evolutionary arguments, and in each case she points forward briefly to their later uses.

In structuring her book in this way, Voss innovatively expands upon an approach previously developed by the history of science-based "Darwin industry." Since the nineteen-seventies, Darwin scholars have compared significant conceptual aspects of Darwin's work with similar ideas of his predecessors (for example, the Malthusian idea of a "struggle for existence," or the natural-theological overtones of Darwin's selecting Nature), often drawing on Darwin's unpublished written notes and letters at the University of Cambridge, to ferret out whom Darwin saw himself as borrowing from, responding to, challenging, or conversing with. Voss does much the same for his visual concepts, drawing on the substantial collection of hitherto underexamined visual material in the Darwin papers - including his own sketches and drawings, clippings, and drawings and photos sent to him by others - as well as going over Darwin's own reading list with their illustrations in mind. To situate his images in a broader context, she delves not only into the intellectual context but also into technical developments in book illustration, such as the invention of lithography and the introduction of photography into books.

The results are rewarding, and show her ability both to synthesize earlier scholarship and to move beyond it. For instance, Voss rehearses in some detail how Darwin's Galapagos finch illustrations depended on John Gould's specialized taxonomic knowledge and his bird-illustration "factory" - subjects known to Darwin specialists and specialists in the history of natural history illustration but less widely known outside these groups. She uses this to make a useful point about how Darwin's famous bird images depended on the labor of many invisible technicians. Elsewhere she deftly weaves together findings from other scholars with new analyses and new material. In her 
examination of classificatory diagrams, for example, she draws on the wide range of scholarship dealing with such topics as the quinarian diagrams of Swainson and MacLeay, the maplike classification diagram of Hugh Strickland, the embryological branching-tree diagrams of Chambers and Martin Barry, and Agassiz's spindle diagrams, to present a full picture of the traditions Darwin had to work with in developing his own famous diagram. Her own interpretation presents Darwin as more of a synthetic visual thinker than previous discussions have argued for (a plausible interpretation in keeping with his synthetic conceptual style). But perhaps the most remarkable part of this analysis is where she takes it next: in contrast to the common wisdom that Darwin never applied the tree concept to any specific groups, she reveals several sketches of evolutionary diagrams from his notes, from both before and after the publication of the Origin, including one of primates from 1868. One might have wished for a fuller discussion of the latter diagram, especially in light of the discussion of Haeckel's tree diagram, but even to have the diagram image placed before us is significant.

The other sections show a similar balance of synthesis and novelty. Her discussion of gorillas in the section on the laughing macaque involves a number of images that will be familiar to scholars of Victorian ape imagery and evolution as well as some that are less well known. But her point - that no one before Darwin had claimed to see a monkey laugh, a position that bolstered the emotional continuity between monkeys and humans - is novel, potent and well supported by her image analysis.

Overall, Voss's analysis of Darwin's images is studded throughout with insights like these, embedded in a broad synthetic picture embracing both natural history illustration and evolutionary ideas. Both newcomers to these subjects and those familiar with them will find this book well worth reading.

In contrast to Voss's orientation toward the history of science and the technical history of book illustration, Jonathan Smith approaches Darwin's pictures from the perspective of Victorian Studies. This field, which has flourished especially in English literature departments, has developed strong lines of analysis both of visual culture and of evolutionary thought in Victorian print culture. Like many literary scholars, Smith opens with a theoretical discussion: on the relationship between image and text in printed works. He seeks to prioritize neither the text (as historians of science tend to do) nor the image (which art historians favor), but to examine the relationship between the two. Here he draws fruitfully on W. J. T. Mitchell's analytical distinction between the "imagetext" - a seamless unit in which image and text work successfully to convey the same message - and the "image/text," which reveals tensions or fissures between the messages conveyed by the two media within one work. Although semioticians and other visual-culture theorists have covered much of this ground, their dense theoretical language has 
tended to be unpalatable to historians of science. Smith shows how much analytical work Mitchell's terms can do, exemplifying how they offer a relatively simple handle for dealing in sophisticated ways with relations between image and text - a problem many historians of science have been grappling with in recent work on science and visuality. Smith thus foregrounds the theoretical problem of how text and image speak to one another in ways that remain less explicit in Voss's book.

An even larger difference in perspective appears in how Smith casts the relationship of Darwin to Victorian visual culture. Rather than focusing mainly on Darwin as a producer of illustrations, the influences on him, and the impact of his mode of picturing on other pictures, Smith situates Darwin's visual work as part of an active and dynamic Victorian battle over the nature of aesthetics. By placing humans under the laws of evolution, Darwin challenged the special "higher" nature of the human sense of beauty and taste. The argument, made most pointedly in The Descent of Man, was already present with the introduction of sexual selection in the Origin: the "taste" of females for some males over others depended on some sort of primitive aesthetic sensibility. Similarly, Darwin's botanical works of the 1860s and 1870s presented the diversity and intricacy of flowers not as the result of God's giving humans something beautiful to meditate on but as the result of naturally selected co-adaptations on the part of insects and pollenproducing plants.

This challenge did not go unmet. Smith sets up John Ruskin as the leading opponent of Darwin's position on aesthetics, and indeed, Ruskin appears in almost every chapter. (In one, Philip Gosse instead plays the role of upholder of theologically ordained beauty and aesthetic sensibility). Ruskin and his allies viewed a naturalistic or evolutionary aesthetics as an anathema: the contemplation of beauty should raise up the sensibilities of the common man to their highest and noblest possible level, not draw them down to the coarseness of brute nature.

Smith's focus on Victorian aesthetic values, and especially his consideration of Ruskin, helps us understand which Darwinian imagetexts he chooses to examine, most of which are strikingly different from Voss's choices. His chapter on Darwin's barnacles allows him to delve into the Victorian romance with the seaside and to explore Philip Gosse's fabulous images of marine invertebrates (one of which spectacularly decorates the book's dust jacket). He highlights the tension between Gosse's popular "visual natural theology" and Darwin's barnacle illustrations, which were simultaneously scientifically austere and open to interpretation in the radical light of transformism. Smith's chapter on Darwin's birds covers much the same territory as Voss's with respect to John Gould's illustrations, and like Voss, he analyzes Darwin's illustrations of the Argus pheasant and its eyespots as revealing a particularly difficult situation with respect to image and evolutionary theory. 
But he pays more attention to Gould's strong commitment to natural theology and its consequences for imagery. Smith persuasively depicts a war of images between Darwin and Gould that ultimately led Darwin to find and adapt bird illustrations by other artists for The Descent of Man. Ruskin then enters the story, as he used Gould's Birds of Great Britain, interpreted as a natural theological text, as a model for his own book on bird natural history, Love's Meinie, which Smith persuasively presents as a direct counter to the materialist threat to morality and aesthetics presented by Darwin's Descent of Man and sexual selection theory.

Similar dynamic and fascinating stories are told in subsequent chapters, as we are treated to welcome analyses of some of Darwin's later works, including his botanical corpus of the 1860s and 1870s (countered by Ruskin's Proserpina); his analysis of faces and his use of photography in Expression of Emotions; and his last work on earthworms, which gives Smith occasion to analyze the conceptual development of the grotesque and the picturesque. In these chapters, Darwin is the first focus, but we are always presented with him facing the problem of how to convey his new ideas visually in terms accessible to his audience, given what they were accustomed to, and then we see how his aesthetic critics countered with their own visual and verbal arguments - arguments that continued long after Darwin's death.

Thus whereas Voss shows an essentially linear picture, with Darwin adopting and adapting existing conventions, and his successors making further use of his visual ideas (often in new directions), Smith presents a much more agonistic field, filled with conflict grounded in deep metaphysical convictions. Voss's book, for its part, offers more detail about bookmaking, and often more about the direct scientific issues Darwin was grappling with, especially issues (such as classification and its visual representation) that are of deep interest to historians of biology. Both books together significantly expand our understanding of Darwin's place in Victorian visual culture, and show how productive the study of visual culture can be, even for some of the most thoroughly analyzed personages and ideas in the history of science.

Lynn K. Nyhart

History of Science

University of Wisconsin

7127 Social Science Building

1180 Observatory Drive

Madison, WI 53706-1393

USA

Email: 1knyhart@wisc.edu 